\title{
Efficacy and Safety of Sahastara Remedy Extract Capsule in Primary Knee Osteoarthritis: A Randomized Double-Blinded Active-Controlled Trial
}

\author{
Narin Kakatum (D), ${ }^{1}$ Piya Pinsornsak $\left(\mathbb{D},{ }^{2}\right.$ Puritat Kanokkangsadal $(\mathbb{D})$, \\ Buncha Ooraikul $\mathbb{D}, 5$ and Arunporn Itharat $\mathbb{D}^{3,4}$ \\ ${ }^{1}$ Student of Doctor of Philosophy (Applied Thai Traditional Medicine) Faculty of Medicine, Thammasat University, Bangkok, \\ Pathum Thani, Thailand \\ ${ }^{2}$ Department of Orthopedics, Faculty of Medicine, Thammasat University, Bangkok, Pathum Thani, Thailand \\ ${ }^{3}$ Department of Applied Thai Traditional Medicine, Faculty of Medicine, Thammasat University, Klongluang, Bangkok, \\ Pathum Thani, Thailand \\ ${ }^{4}$ Center of Excellence on Applied Thai Traditional Medicine Research (CEATMR), Faculty of Medicine, Thammasat University, \\ Klongluang, Bangkok, Pathum Thani, Thailand \\ ${ }^{5}$ Department of Agricultural Food and Nutritional Science, Faculty of Agricultural Life and Environmental Sciences, \\ University of Alberta, Alberta T6G 2P5, Edmonton, Canada
}

Correspondence should be addressed to Arunporn Itharat; iarunporn@yahoo.com

Received 25 October 2020; Revised 5 January 2021; Accepted 7 January 2021; Published 18 January 2021

Academic Editor: Wei Lei

Copyright (C) 2021 Narin Kakatum et al. This is an open access article distributed under the Creative Commons Attribution License, which permits unrestricted use, distribution, and reproduction in any medium, provided the original work is properly cited.

\begin{abstract}
Sahastara (SHT) remedy is a Thai traditional medicine described in the Thai National List of Essential Medicine (NLEM) for the relief of muscle pain. The purpose of this study was to investigate the efficacy and safety of SHT remedy extract capsule for treating primary OA. A phase 2, double-blind, randomized, and controlled trial study was used to determine the clinical efficacy and safety of SHT in comparison with diclofenac for the treatment of knee OA. The outcome of reduce pain was measured from VAS, 100 meter time walk, and the WOMAC score of day 14 and day 28 which should reduce significantly when compared with day 0 and should be equal with or better than diclofenac. Blood pressure and blood chemistry values at day 14 and day 28 did not change when compared with day 0 . The results found that SHT remedy ethanolic extract capsule can reduce all OA knee scores at day 14 and day 28 significantly when compared with day 0 and also no significant difference with diclofenac $(P>0.05)$. The SHT also showed safety values on blood pressure and blood chemistry. The SHT was observed that it had no serious side effect. The results of this study are the first report of using the SHT ethanolic extract capsule in the treatment of primary osteoarthritis of the knee. It can be recommended as an anti-inflammatory herbal drug for reducing pain in knee osteoarthritis patients.
\end{abstract}

\section{Introduction}

Osteoarthritis (OA) is the most common joint disease which occurs more frequently in males before the age of 45 and more frequently in females after 55 years of age. Osteoarthritis commonly occurs in the hands, feet, spine, and large weight-bearing joints, such as hips and knees. OA with no known cause is referred to as primary osteoarthritis. When the cause is known, it is referred to as secondary osteoarthritis. Cartilage changes when the dynamics of biology, biochemistry, and bone structure around it changed. In the elderly, involvement of synovial fluid is most common. The pain is an important clinical complaint [1]. The oral and topical NSAIDs are most commonly used to relieve pain in OA knee patients. Diclofenac was used as an active control which showed a superior effect for osteoarthritis [2]. Not only NSIADs were used for OA treatment but alternative medicine was also commonly used, including acupuncture, Thai massage, sesame oil, yellow oil, and herbal medicine [3-5]. 
Sahastara (SHT) is a remedy in the National Essential Drugs List (2011) which comprises 21 species of herbs as shown in Table 1. Previous research studies supported antiinflammatory activity of SHT remedy. $\mathrm{IC}_{50}$ values of SHT ethanolic extract on nitric oxide and COX-2 inhibition were $2.81 \mu \mathrm{g} / \mathrm{ml}$ and $16.97 \mu \mathrm{g} / \mathrm{ml}$, respectively [6]. SHT ethanolic extract exerted similar activity to NSAIDs. It was also found that SHT extract had no mutagenic effects on Salmonella typhimurium TA98 and TA100 isolated from patients [7]. The effectiveness and safety of the treatment with $3000 \mathrm{mg} /$ day of powder SHT for primary osteoarthritic knee, as compared to $75 \mathrm{mg}$ /day of diclofenac over 28 days, indicated that the SHT powder formulation was as effective as diclofenac. Furthermore, the SHT powder remedy was not toxic to the liver and kidney [8].

A previous study showed that SHT ethanolic extract exerted a higher inhibitory effect on nitric oxide (NO) release in activated murine macrophages cell line (RAW 264.7) than indomethacin $\left(\mathrm{IC}_{50}=2.81\right.$ and $20.32 \mu \mathrm{g} / \mathrm{mL}$, respectively) [6]. SHT ethanolic extract and its components were also tested for anti-inflammation by their inhibitory effects on LPS-stimulated $\mathrm{PGE}_{2}$ release in RAW 264.7 cells [9]. The SHT extract and indomethacin (positive control) had $\mathrm{IC}_{50}$ values of 16.97 and $1.00 \mu \mathrm{g} / \mathrm{mL}$, respectively. $P$. nigrum $[10,11]$ and $P$. retrofractum $[12,13]$ which are the main ingredients (33.42\%) of SHT preparation also showed high anti-inflammatory activity on $\mathrm{PGE}_{2}$ release with $\mathrm{IC}_{50}$ of 17.70 and $23.08 \mu \mathrm{g} / \mathrm{mL}$, respectively [6]. Piperine, a main component of both Piper species, exerted anti-inflammatory activity on human OA chondrocytes by inhibiting the IL-1 $\beta$ which induces the production of $\mathrm{PGE}_{2}$ and $\mathrm{NO}[14,15]$. Moreover, previous clinical studies on both SHT remedy (in powder form) and diclofenac had shown a significant reduction of VAS pain scores $[8,16]$. The ethanolic extract of SHT in the capsule form was also studied on healthy volunteers with 300 and $600 \mathrm{mg} /$ day for 28 days and showed safety on the kidney, liver, and blood [17]. The pharmacokinetic of piperine was also studied with oral administration dosing of 100-200 mg of SHT extract to healthy Thai volunteers and demonstrated that piperine was detectable in plasma for at least 48 hours with evidence of enterohepatic recirculation [18]. Thus, the objective of this research was to investigate the clinical efficacy of SHT ethanolic extract capsule compared with the conventional anti-inflammatory drug, diclofenac, in osteoarthritic knee patients and its safety over the four weeks of continuous treatment. This is the first study to report on clinical efficacy and safety of SHT ethanolic extract capsule in OA knee patients in order to determine whether further development of the SHT ethanolic extract capsule as medicine for OA is warranted. This study was also performed to determine whether the SHT ethanolic extract capsules can reduce the number of SHT powder capsules currently taken by the patients and hence increase the efficacy of the treatment.

\section{Materials and Methods}

2.1. Research Design. The research was a randomized, double-blind, and controlled trial (phase 2) designed to study the clinical efficacy and safety of the SHT remedy ethanolic extract capsule in comparison to diclofenac for the treatment of knee OA at Thammasat University Hospital, Pathum Thani Province, Thailand. It was approved by the Medical Ethics Committee of the Faculty of Medicine, Thammasat University, which was accepted by the Thai FDA (MTU-EC-TM-2-116_2/59). It was also registered at the Clinical Trials.gov (NCT04591795).

2.2. Subjects. Sixty-six outpatients from Department of Orthopedics, Thammasat University Hospital, between 40 and 70 years of age were recruited for this study. They were diagnosed with primary osteoarthritis of the knee according to the American College of Rheumatology's clinical and radiological criteria [19]. The patients who were included in this study had no plan for knee arthroplasty in three months, and their minimum pain symptom severity was ensured by the visual analogue scale (VAS) score of at least $20 \mathrm{~mm}$ from $100 \mathrm{~mm}$. The exclusion criteria were patients rated with severe knee osteoarthritis (grade 4, based on the Kellgren and Lawrence radiographic system) [20], patients with serious medical conditions such as uncontrolled hypertension (BP $>140 / 90 \mathrm{mmHg}$ ), severe GI disease, congestive heart disease, liver and renal dysfunction, and obese patients with body mass index (BMI) more than $32 \mathrm{~kg} / \mathrm{m}^{2}$.

2.3. Sample Size. The estimate of the sample size was based on the previous phase 2 clinical trial of the SHT powder capsule in the treatment of primary osteoarthritis [8]. The lower level of average VAS pain scores from the previous clinical trial was $44.1($ S.D. $=23.5)$ for SHT powder capsules and 31.8 (S.D. $=22.8$ ) for diclofenac, based on statistical calculations with Stata computer programs at the power of 80 and type I (alpha) error of 0.05 . The calculated number of volunteers for each of the two treatments was 28 , thus requiring 56 people for both treatments. Allowing for a dropout of $10 \%$, i.e., six additional volunteers, a minimum of 62 recruits would be required to satisfy the clinical trial protocol. The following equation was used in the calculation:

$$
\begin{aligned}
n_{1} & =\frac{\left(z_{1}-(\alpha / 2)+z_{1}-\beta\right)^{2}\left[\sigma_{1}^{2}+\left(\sigma_{2}^{2} / r\right)\right]}{\Delta^{2}}, \\
r & =\frac{n_{2}}{n_{1}} \\
\Delta & =\mu_{1}-\mu_{2} .
\end{aligned}
$$

In this experiment, a total of 75 volunteers were screened and 66 were chosen, with 33 each allocated to SHT and diclofenac treatment groups.

2.4. Drug Preparation. The SHT remedy was prepared according to Thai National List of Essential Medicine 2011 (NLEM). The proportion of medicinal plant ingredients and their sources is shown in Table 1. All plants were cleaned immediately of extraneous materials, dried at $50^{\circ} \mathrm{C}$, weighed according to the SHT recipe, mixed together, and ground to 
TABLe 1: Medicinal plants in Sahastara remedy formulation (for $1,000 \mathrm{~g}$ of powder drug).

\begin{tabular}{|c|c|c|c|c|c|}
\hline Thai name & Scientific name & Specimen voucher & Part used & Weight $(\mathrm{g})$ & Source \\
\hline Prik-Thai & Piper nigrum Linn. & SKP146161401 & Fruit & 240 & Chanthaburi, Thailand \\
\hline Jet-Ta-Mul-Plerng-Dang & Plumbago indica Linn. & SKP148160901 & Root & 224 & Laos \\
\hline Sa-Mhor-Thai & Terminalia chebula Retz. & SKP049200301 & Fruit & 104 & Sa Kaeo, Thailand \\
\hline Dee-Plee & Piper retrofractum Vahl. & SKP146160301 & Fruit & 96 & Chanthaburi, Thailand \\
\hline Tong-Tank & Baliospermum montanum Muell. A. & SKP121021301 & Root & 80 & Kanchanaburi, Thailand \\
\hline Wan-Nam & Acorus calamus Linn. & SKP015010301 & Rhizome & 88 & Nonthaburi, Thailand \\
\hline Has-Sa-Khun-Tade & Kleinhovia hospita Linn. & SKP183110801 & Root & 48 & Kanchanaburi, Thailand \\
\hline Ka-Ra-Boon & Cinnamomum camphora Linn. & SKP096030301 & - & 14 & China \\
\hline Dok-Chan & Myristica fragrans Houtt. & SKP121130601 & Aril of seed & 13 & China \\
\hline Luk-Chan & Myristica fragrans Houtt. & SKP121130601 & Seed & 12 & China \\
\hline Tien-Dang & Lepidium sativum Linn. & SKP057121901 & Seed & 11 & India \\
\hline Tien-Ta-Tuk-Ka-Tan & Anethum graveolens Linn. & SKP199010701 & Fruit & 10 & India \\
\hline Ma-Ha-Hing & Ferula asafoetida Linn. & SKP199060101 & Resin & 10 & India \\
\hline Tien-Sut-Ta-but & Pimpinella anisum Linn. & SKP199160101 & Fruit & 9 & China \\
\hline Tien-Khao & Cuminum cyminum Linn. & SKP199030301 & Fruit & 8 & India \\
\hline Jing-Jor & Merremia vitifolia & SKP054132201 & Root & 8 & Kanchanaburi, Thailand \\
\hline Tien-Dum & Nigella sativa Linn. & SKP160141901 & Seed & 7 & China \\
\hline Kote-Kag-Kra & Anacyclus pyrethrum (L.) DC. & SKP051011601 & Root & 6 & China \\
\hline Kote-Ka-Mao & Atractylodes lancea (Thunb) DC. & SKP051011201 & Rhizome & 5 & China \\
\hline Kote-Kan-Prao & Picrorhiza kurroa Benth. & SKP177161101 & Root & 4 & India \\
\hline Kote-Pung-Pla & Terminalia chebula Retz. (Gall) & SKP019200301 & Gall & 3 & India \\
\hline
\end{tabular}

pass through sieve number 80 . The ground SHT was macerated at room temperature with $95 \%$ ethanol $(\mathrm{L} / \mathrm{S}=2: 1)$ for three days and filtered through a Whatman number 1 filter paper. The residue was further macerated with the same solvent two more times. The extracts were combined and concentrated with a rotary evaporator (Rotavapor R-205, Buchi, Switzerland). Quality control of all plant ingredients and SHT preparation was based on Thai herbal pharmacopoeia (appearance, chemical fingerprints, disintegration, microbial contamination, heavy metal contamination, and loss on drying). Piperine in SHT powder and extract was analyzed by high-performance chromatography (HPLC) to ensure that the piperine content in the SHT ethanolic extract was not less than $19 \mathrm{mg} / \mathrm{g}$. The dry extract was pulverized and filled in $500 \mathrm{mg}$ capsules with excipient (the concentration of SHT extract is $100 \mathrm{mg}$ per capsule). Diclofenac sodium, $25 \mathrm{mg}$ enteric-coated tablets (Voltaren ${ }^{\circledR}$, Novartis), for oral administration, was filled into $500 \mathrm{mg}$ capsules (1 tablet of diclofenac sodium per capsule). Lactose monohydrate as a placebo was also prepared in capsules $(500 \mathrm{mg}$ per capsule). Omeprazole (20 mg) (Miracid ${ }^{\circledR}$, Berlin) was used as an open labeled medication.

2.5. Procedures. The patients who met the inclusion criteria were informed, signed a consent form, and divided randomly into two groups of treatment, using a computergenerated program, by an individual who did not have any contact with the investigators. The patients received a randomized number sequentially from a secret random list. Treatment assignment was also concealed from all investigators involved in the trial. Each patient received the same appearance of the treatment that contains treatment code, which was opened only in medical emergency condition. The masking was opened after data analysis. In the clinical trial, demographic data, clinical signs and symptoms, laboratory tests (complete blood count, fasting blood sugar, lipid profile, the liver function test, the renal function test, and urine analysis), visual analogue scale (VAS) for pain, 100 meter walk times, and the Western Ontario and McMaster Universities (WOMAC) index scores were collected on the first visit for baseline data and after receiving the treatment on days 14 and 28 [21, 22].

2.6. Drug Administration. The patients were divided randomly into two groups. Those in group 1 received the SHT extract $300 \mathrm{mg} /$ day (one capsule of $100 \mathrm{mg}$ SHT ethanolic extract three times daily before meals). This was the equivalent dose of SHT remedy that was indicated in NLEM at $3,000 \mathrm{mg} /$ day of SHT remedy in the powder form. The patients in group 2 received diclofenac sodium $75 \mathrm{mg} /$ day $(1$ capsule of $25 \mathrm{mg}$ diclofenac three times daily after meals) [22]. In addition, the patients in both groups received $20 \mathrm{mg}$ of omeprazole, 1 capsule before breakfast for the prevention of adverse gastrointestinal effects [8].

Clinical assessment: the treatments were completed in 28 days with the clinical and laboratory assessments at the $14^{\text {th }}$ and $28^{\text {th }}$ days. After treatments, a global assessment was performed on the patients at the last visit. The clinical efficacy was evaluated from the VAS pain scores, the 100 meter walk times, the WOMAC index scores (ranging from 0 to 96) at days 0,14 , and 28 , and the global assessment on a $0-4$ Likert scale (0, none; 4 , excellent). The clinical efficacy and safety outcomes were evaluated by clinical examinations and laboratory analyses.

Toxicity of the drugs was considered in excluding patients following the USFDA guidance for the industry in the toxicity grading scale such as creatinine more than $1.7 \mathrm{mg} /$ 
$\mathrm{dL}, \mathrm{BUN}$ more than $26 \mathrm{mg} / \mathrm{dL}$ AST, and ALT more than $2.5 \mathrm{x}$ upper limit of normal (ULN) or ALP more than 2.0x ULN.

2.7. Statistical Analysis. The changes in mean values from baseline to days 14 and 28 for each group were analyzed by the repeated measured analysis of variance (ANOVA) or Friedman's test. The mean values between the two groups were compared using Student's $t$ test or the Mann-Whitney $U$ test. The comparison of the global assessments of the two groups was analyzed by the chi-square test, with $P<0.05$ indicating a significant difference. SPSS software (version 16.0, USA) was used to analyze the data.

\section{Results}

In this clinical trial, 75 volunteers were screened and 66 patients were chosen and divided into two groups of 33 people each, one group receiving SHT ethanolic extract capsules and the other receiving diclofenac capsules. Both groups showed no significant differences in their baseline characteristics and the radiographic grading (Table 2). Originally, 66 patients were chosen for the study, but only 63 (95.45\%) patients completed the study (32 in the SHT group and 31 in the diclofenac group). Three patients dropped out at the follow-up visits with unrelated intervention and nonserious reasons (two patients missed appointments, and one patient suffered from a traumatic wrist injury that required surgery) (Figure 1).

\subsection{Efficacy of SHT Extract Capsule in Primary Osteoarthritis} Patients. The clinical trial results showed that the SHT ethanolic extract capsule had the ability to relieve pain, reduce inflammation, improve daily life activities, decrease the WOMAC scores, and 100 meter walk times (Table 3). Comparison of all criteria (WOMAC scores on all physical index and 100 meters walk) between SHT ethanolic extract capsule and diclofenac showed no significant difference $(P>0.05)$, but the VAS score of SHT at day 28 was higher than diclofenac and was significantly different $(P=0.01)$.

\subsection{Evaluation of the Overall Treatment (Global Assessment).} To evaluate the overall effectiveness of the OA treatment with SHT extract in comparison with diclofenac (global assessment), the symptoms were monitored at day 28 , using Likert scale scores, and the results showed no significant difference between the two groups (Table 4).

3.3. Safety Evaluation. The safety data of SHT and diclofenac groups shown as the results of blood pressure, blood chemistry of liver function, renal function, and the other blood chemistry such as complete blood count, fasting blood sugar, and lipid profile are shown in Table 5.

The systolic and diastolic blood pressure measurements were not significantly different from the baseline nor between the two groups. All patients were examined for blood urine nitrogen (BUN) and creatinine in renal function tests and for aspartate transaminase (AST), alanine aminotransferase (ALT), and alkaline phosphatase (ALP) in liver function tests at days 14 and 28. The renal function was similar in both groups when compared with their baseline values. The liver function tests of the SHT group showed no effect in the AST, ALT, and ALP values. In contrast, the AST and ALT values increased significantly after the treatment with diclofenac. The results of other blood chemistry such as complete blood count, fasting blood sugar, and lipid profile showed no significant difference between the two drug groups.

3.4. Adverse Effect. The adverse effects found in both groups were abdominal discomfort, $31.25 \%$ among the subjects in the SHT group and $22.58 \%$ in the diclofenac group. However, the common side effect of the SHT extract-treated group was belching, while that in the diclofenac-treated group was gastric pain (Table 6).

\section{Discussion}

The clinical efficacy of SHT might be described from the previous studies of five anti-inflammatory markers in Sahastara remedy such as piperine, ellagic acid, gallic acid, $\beta$-asarone, and plumbagin. Piperine as the main component of the SHT remedy was found to reduce the percentages of iNOS, elastin, and smooth muscle cells actin and was shown to decrease blood pressure from the third week of treatment [23]. The ethanolic extract of pepper showed anti-inflammatory activity in vitro, and piperine as the isolated compound was tested on interleukin $1 \beta$ - (IL-1 $\beta$-) stimulated fibroblast-like synoviocytes derived from the OA knee patients [15]. Ellagic acid as an active compound could reduce inflammation on rat paw edema at 4 hours [24]. Gallic acid $(10 \mu \mathrm{M})$ isolated from Terminalia chebula Retz. blocked TNF- $\alpha$ and IL-6 secretion induced by PMA plus and A23187 in HMC-1 cells (68.4\% inhibition in TNF- $\alpha$ and $49.8 \%$ inhibition in IL-6) [25]. $\beta$-Asarone from Acorus calamus at the dose of $50 \mu \mathrm{M}$ inhibited the production of proinflammatory cytokines, especially IL- $1 \beta$ and TNF- $\alpha(P<0.05)$. [26]. Plumbagin from Plumbago indica inhibited inflammatory cytokine (IL-2, IL-4, IL-6, and IFN- $\gamma$ ) production in activated lymphocytes which was stimulated with con. A $(5 \mu \mathrm{g} / \mathrm{ml})$ following which plumbagin was added at the indicated times, and the cells were cultured for $24 \mathrm{~h}$ at $37^{\circ} \mathrm{C}(P<0.01)$ [27]. Asafoetida as a component in SHT has ever been reported that it showed good efficacy on reducing inflammation from dental plaque and gingivitis compared with chlorhexidine gluconate [28].

Diclofenac is an NSAID used as a control group. It is slightly better than a placebo over all of the specific treatments and increased with greater baseline pain severity $(P<0.001)[2]$.

Five parameters were measured in this study: the level of knee pain by VAS (mm) after walk on 100 meters, the 100 meters walking time, and the 3 WOMAC index scores (pain index, stiffness index, and physical function index). The levels of knee pain in the SHT extract group $(n=32)$ were reduced significantly 
TABLE 2: Baseline characteristics of volunteers.

\begin{tabular}{|c|c|c|c|}
\hline Characteristics & Sahastara $(n=32)$ & Diclofenac $(n=31)$ & $p$ value* \\
\hline Female, no. (\%) & $29(87.87)$ & $30(90.90)$ & $0.68^{\mathrm{C}}$ \\
\hline Age, mean (SD) & $58.48(6.98)$ & $59.00(6.1)$ & $0.75^{t}$ \\
\hline Weight $(\mathrm{Kg})$, mean $(\mathrm{SD})$ & $64.15(7.6)$ & $60.53(9.9)$ & $0.10^{\mathrm{t}}$ \\
\hline Height $(\mathrm{cm})$, mean $(\mathrm{SD})$ & $1.52(0.08)$ & $1.54(0.06)$ & $0.23^{\mathrm{m}}$ \\
\hline BMI, mean (SD) & $27.55(3.45)$ & $25.25(4.13)$ & $0.19^{\mathrm{m}}$ \\
\hline \multicolumn{4}{|l|}{ Walk 100 meters } \\
\hline Knee pain level VAS (mm), mean (SD) & $57.84(2.19)$ & $54.61(14.50)$ & $0.28^{\mathrm{t}}$ \\
\hline 100 meters walk duration. $(\mathrm{m} / \mathrm{s})$, mean $(\mathrm{SD})$ & $138.86(40.38)$ & $130.41(5.96)$ & $0.44^{\mathrm{m}}$ \\
\hline \multicolumn{4}{|l|}{ WOMAC index, mean (SD) } \\
\hline Pain index & $8.33(2.23)$ & $8.15(4.21)$ & $0.23^{\mathrm{m}}$ \\
\hline Stiffness index & $1.72(1.79)$ & $1.71(1.95)$ & $0.83^{\mathrm{m}}$ \\
\hline Physical index & $32.66(8.77)$ & $30.93(10.83)$ & $0.44^{\mathrm{m}}$ \\
\hline Total score & $42.72(10.53)$ & $40.81(15.27)$ & $0.27^{\mathrm{m}}$ \\
\hline \multicolumn{4}{|l|}{ Kellgren and Lawrence $\mathrm{X}$-ray grade } \\
\hline Grade 1 & $7(21.88)$ & $4(12.90)$ & \\
\hline Grade 2 & $7(21.88)$ & $15(48.39)$ & $0.10^{\mathrm{C}}$ \\
\hline Grade 3 & $18(56.25)$ & $12(38.70)$ & \\
\hline Total & $32(100)$ & $31(100)$ & \\
\hline
\end{tabular}

${ }^{*}$ Statistical analysis. ${ }^{\mathrm{t}}$ Independent sample $t$ test; ${ }^{\mathrm{c}}$ chi-square test; ${ }^{\mathrm{m}}=$ Mann-Whitney $U$ test.

$(p<0.01)$ in both follow-ups $\left(14^{\text {th }}\right.$ and $28^{\text {th }}$ days $)$. However, the levels of knee pain in the diclofenac-treated group $(n=31)$ was significant after 28 days of treatment $(p<0.01)$. Comparison between SHT extract and diclofenac groups on the VAS score which evaluated the pain score after 100 meters walk showed that they were not significantly different at day 0 and day 14 but differed significantly at day $28(p<0.01)$. The results showed that SHT extract surpassed diclofenac in reducing knee pain.

The 100 meters walk durations were reduced in both follow-ups $\left(14^{\text {th }}\right.$ and $28^{\text {th }}$ days). However, in the SHT extract group $(n=32)$, the reduction was significant after 28 days of treatment $(p<0.05)$. Comparison between SHT and diclofenac groups showed that they were not significantly different at days 0,14 , and $28(p>0.05)$.

The WOMAC index scores (pain index, stiffness index, and physical function index) in both groups were reduced significantly $(p<0.01)$ in both follow-ups $\left(14^{\text {th }}\right.$ and $28^{\text {th }}$ days). Comparison between SHT and diclofenac groups showed that they were not significantly different at days 0 , 14 , and 28. These results were consistent with those in the study on knee pain using SHT powder capsules which showed significant reduction in the mean VAS pain scores sooner than diclofenac [18]. Another study on office syndrome using SHT powder capsules in comparison with diclofenac also showed equal effectiveness in reducing pain [16]. However, this study found that SHT extract showed good reduction in stiffness index, significantly different with day 0 and no significant difference with diclofenac. SHT extract showed different results when compared with SHT powder; in that, SHT extract showed better efficacy on stiffness reduction than SHT powder [5]. In addition, the total stiffness score of SHT extract decreased on days 14 and 28 , equal to that of diclofenac. However, the previous result of SHT powder showed a significant difference of the total score only on day 28 . These results indicated that SHT extract was more effective on OA knee patients than SHT powder. Both extract and powder of SHT showed no significant difference when compared with diclofenac [5].

For the safety evaluation, blood pressure was shown to increase in the diclofenac group by $50 \%$ [29]. This is similar to the results of this study which showed increased blood pressure and relief of pain. However, the SHT group did not show any significant change in blood pressure as indicated by the study with SHT powder drug in rat which showed no effect on blood pressure and the vasculoprotective effect in hypertensive and NO-impaired rats [30], which is similar to another SHT powder drug study in OA knee patients [7].

With regard to the adverse side effects of SHT powder and diclofenac, a previous study [8] reported that both groups developed abdominal discomfort. However, the side effect from the SHT extract group was minor (Table 6), i.e., only belching which is normally the effect of spicy taste of plant components, such as Piper spp., while that of diclofenac was a more serious gastric pain.

SHT ethanolic extract has no effect on blood pressure and renal and liver functions, which indicates that it is safe. Similar results have been reported previously on SHT powder. Diclofenac in this study showed an increase in the liver function value but remained within the normal range. This is similar to two previous reports $[7,18]$.

Important criteria for drugs to be included in the National Essential Drugs List are efficacy and human safety. SHT powder capsule is included in the National Essential Drugs List because it is shown to be a safe and effective drug for pain relief. Taking the drug in the form of powder at the dose of $6 \times 500 \mathrm{mg}$ capsules/day might affect patient compliance with the medication. This study used the SHT ethanolic extract capsules at a much smaller dose of $3 \times 100 \mathrm{mg}$ capsules/day and thus significantly reduced the number of capsules taken by the patients. This should increase the efficacy of the treatment since it would 


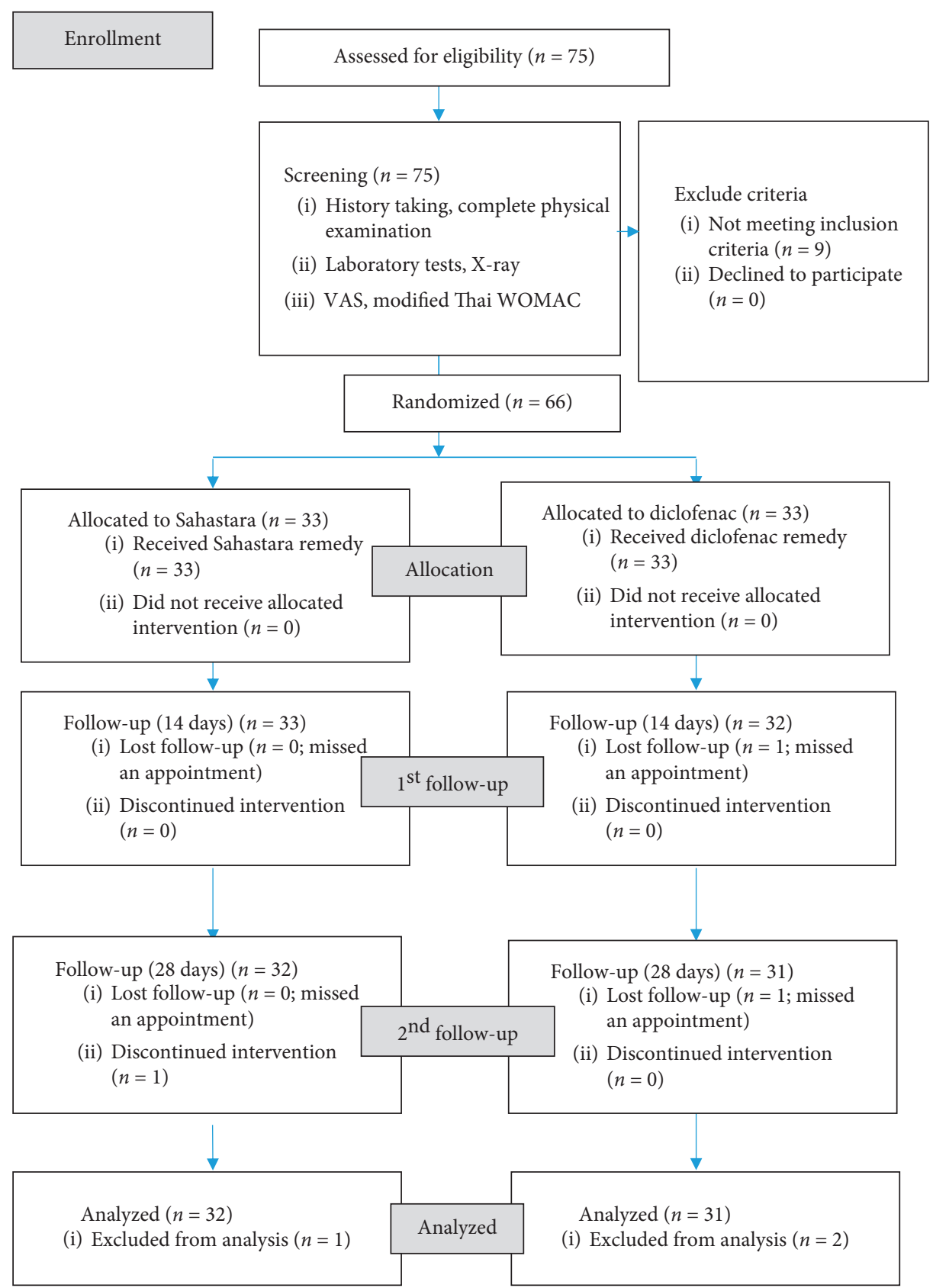

FIgURE 1: Flow chart of the study design.

TABle 3: Experimental results of Sahastara ethanolic extract and diclofenac.

\begin{tabular}{|c|c|c|c|c|}
\hline \multirow{2}{*}{ Data } & \multirow{2}{*}{ Follow-up } & \multicolumn{2}{|c|}{ Treatment* } & \multirow{2}{*}{$p$ value $^{*}$} \\
\hline & & Sahastara $(n=32)$ & Diclofenac $(n=31)$ & \\
\hline \multicolumn{5}{|l|}{ Walk 100 meters } \\
\hline \multirow{3}{*}{ Knee pain levels: VAS (mm) } & Day 0 & $57.84(2.19)$ & $54.61(14.50)$ & $0.28^{\mathrm{m}}$ \\
\hline & Day 14 & $46.12(2.57)^{\dagger \dagger}$ & $41.09(11.01)$ & $0.82^{\mathrm{m}}$ \\
\hline & Day 28 & $36.46(10.90)^{\dagger \dagger}$ & $29.77(8.86)^{\dagger \dagger}$ & $0.01^{\mathrm{m}}$ \\
\hline \multirow{3}{*}{100 meters walk (seconds) } & Day 0 & $138.86(40.38)$ & $130.41(5.96)$ & $0.44^{\mathrm{m}}$ \\
\hline & Day 14 & $129.37(29.28)$ & $120.70(4.14)^{\dagger}$ & $0.11^{\mathrm{m}}$ \\
\hline & Day 28 & $122.65(26.46)^{\dagger}$ & $111.51(3.83)^{\dagger}$ & $0.13^{\mathrm{m}}$ \\
\hline \multicolumn{5}{|l|}{ WOMAC index scores } \\
\hline \multirow{3}{*}{ Pain index } & Day 0 & $8.25(2.21)$ & $7.64(3.02)$ & $0.23^{\mathrm{m}}$ \\
\hline & Day 14 & $5.93(2.52)^{\dagger \dagger}$ & $5.61(2.4)^{\dagger}$ & $0.64^{\mathrm{m}}$ \\
\hline & Day 28 & $3.81(2.05)^{\dagger \dagger}$ & $3.51(1.94)^{\dagger \dagger}$ & $0.63^{\mathrm{m}}$ \\
\hline
\end{tabular}


TABLE 3: Continued.

\begin{tabular}{|c|c|c|c|c|}
\hline \multirow{2}{*}{ Data } & \multirow{2}{*}{ Follow-up } & \multicolumn{2}{|c|}{ Treatment* } & \multirow{2}{*}{$p$ value ${ }^{* *}$} \\
\hline & & Sahastara $(n=32)$ & Diclofenac $(n=31)$ & \\
\hline \multirow{3}{*}{ Stiffness index } & Day 0 & $1.75(1.81)$ & $1.69(1.81)$ & $0.83^{\mathrm{m}}$ \\
\hline & Day 14 & $0.7(1.34)^{\dagger}$ & $0.57(1.11)^{\dagger \dagger}$ & $0.44^{\mathrm{m}}$ \\
\hline & Day 28 & $0.09(0.39)^{\dagger \dagger}$ & $0.09(0.34)^{\dagger \dagger}$ & $0.64^{\mathrm{m}}$ \\
\hline \multirow{3}{*}{ Physical function index } & Day 0 & $32.53(8.8)$ & $31.66(9.8)$ & $044^{\mathrm{m}}$ \\
\hline & Day 14 & $24.87(9.02)^{\dagger \dagger}$ & $24.87(9.02)^{\dagger \dagger}$ & $0.19^{\mathrm{m}}$ \\
\hline & Day 28 & $17.65(7.78)^{\dagger \dagger}$ & $16.92(7.6)^{\dagger \dagger}$ & $0.51^{\mathrm{m}}$ \\
\hline \multirow{3}{*}{ Total score } & Day 0 & $42.53(1.88)$ & $40.06(14.22)$ & $0.27^{\mathrm{m}}$ \\
\hline & Day 14 & $32.96(1.97)^{\dagger \dagger}$ & $28.61(11.41)^{\dagger \dagger}$ & $0.21^{\mathrm{m}}$ \\
\hline & Day 28 & $21.93(1.75)^{\dagger \dagger}$ & $19.77(8.75)^{\dagger \dagger}$ & $0.37^{\mathrm{m}}$ \\
\hline
\end{tabular}

${ }^{*}$ Data represent mean (SD). ${ }^{* *}$ Statistical analysis. ${ }^{\mathrm{m}}$ Mann-Whitney $U$ test. For all within group statistical analysis: repeated measure ANOVA. ${ }^{\dagger}$ Significant difference from day 0 within the group $(P<0.05) ;{ }^{\dagger \dagger}$ significant difference from day 0 within the group $(P<0.01)$.

TABLE 4: Overall assessment of treatments evaluated at day 28.

\begin{tabular}{|c|c|c|c|}
\hline Evaluate overall treatment (global assessment) & Sahastara, no. (\%) & Diclofenac, no. (\%) & $p$ value between groups \\
\hline 0 (none) & $0(0)$ & $0(0)$ & \multirow{6}{*}{$0.75^{\mathrm{c}}$} \\
\hline 1 (mild better) & $1(3.12)$ & $1(3.23)$ & \\
\hline 2 (moderate better) & $11(34.37)$ & $8(25.80)$ & \\
\hline 3 (very much better) & $20(62.50)$ & $22(70.96)$ & \\
\hline 4 (excellent) & $0(0)$ & $0(0)$ & \\
\hline Total & 32 & 31 & \\
\hline
\end{tabular}

${ }^{{ }^{C} \text { Chi-square. }}$

TABLE 5: Effect of SHT and diclofenac on blood pressure, renal functions, liver functions and blood chemistry.

\begin{tabular}{|c|c|c|c|c|}
\hline \multirow{2}{*}{ Data } & \multirow{2}{*}{ Follow-up } & \multicolumn{2}{|c|}{ Treatment* } & \multirow{2}{*}{$p$ value ${ }^{* *}$} \\
\hline & & Sahastara $(n=32)$ & Diclofenac $(n=31)$ & \\
\hline \multicolumn{5}{|l|}{ Blood pressure } \\
\hline \multirow{3}{*}{ Systolic (normal< $140 \mathrm{mmHg}$ ) } & Day 0 & $128.39(8.43)$ & $129.55(7.57)$ & $0.57^{\mathbf{m}}$ \\
\hline & Day 14 & $127.36(7.63)$ & $130.94(8.32)^{\dagger}$ & $0.66^{\mathrm{m}}$ \\
\hline & Day 28 & $127.31(7.32)$ & $131.71(8.09)^{\dagger \dagger}$ & $0.01^{\mathrm{m}}$ \\
\hline \multirow{3}{*}{ Diastolic (normal $90 \mathrm{mmHg}$ ) } & Day 0 & $80.45(7.25)$ & $81.21(6.88)$ & $0.67^{\mathbf{m}}$ \\
\hline & Day 14 & $80.45(5.06)$ & $81.81(6.96)$ & $0.38^{\mathbf{m}}$ \\
\hline & Day 28 & $79.19(5.01)$ & $80.52(7.40)^{\dagger}$ & $0.02^{\mathbf{m}}$ \\
\hline \multicolumn{5}{|l|}{ Renal functions } \\
\hline \multirow{3}{*}{ Blood urea nitrogen, BUN $(\mathrm{mg} / \mathrm{dL})($ normal range $=7.0-18.0)$} & Day 0 & $14.89(4.3)$ & $14.41(5.87)$ & $0.27^{\mathbf{m}}$ \\
\hline & Day 14 & $16.68(5.76)$ & $14.97(4.11)$ & $0.40^{\mathbf{m}}$ \\
\hline & Day 28 & $15.19(3.90)$ & $15.38(5.00)$ & $0.91^{\mathrm{m}}$ \\
\hline \multirow{3}{*}{ Creatinine (normal range $=0.8-1.3$ ) } & Day 0 & $0.74(0.12)$ & $0.72(0.22)$ & $0.14^{\mathbf{m}}$ \\
\hline & Day 14 & $0.76(0.13)$ & $0.75(0.12)$ & $0.41^{\mathrm{m}}$ \\
\hline & Day 28 & $0.74(0.15)$ & $0.94(1.11)$ & $0.45^{\mathrm{m}}$ \\
\hline \multicolumn{5}{|l|}{ Liver function tests } \\
\hline \multirow{3}{*}{ AST $(\mathrm{U} / \mathrm{L})($ normal range $=15-37 \mathrm{U} / \mathrm{L})$} & Day 0 & $24.71(6.56)$ & $24.03(6.53)$ & $0.55^{\mathrm{m}}$ \\
\hline & Day 14 & $26.75(10.88)$ & $28.25(7.7)$ & $0.11^{\mathrm{m}}$ \\
\hline & Day 28 & $27.59(9.39)$ & $29.74(11.33)^{\dagger}$ & $0.48^{\mathbf{m}}$ \\
\hline \multirow{3}{*}{ ALT $(\mathrm{U} / \mathrm{L})($ normal range $=30-65 \mathrm{U} / \mathrm{L})$} & Day 0 & $32.18(9.55)$ & $28.55(8.4)$ & $0.86^{\mathbf{m}}$ \\
\hline & Day 14 & $35.56(15.39)$ & $34.06(11.59)^{\dagger}$ & $0.93^{\mathbf{m}}$ \\
\hline & Day 28 & $33.87(15.81$ & $38.61(20.15)^{\dagger}$ & $0.25^{\mathrm{m}}$ \\
\hline \multirow{3}{*}{$\operatorname{ALP}(\mathrm{U} / \mathrm{L})($ normal range $=30-120 \mathrm{U} / \mathrm{L})$} & Day 0 & $74.27(20.18)$ & $78.96(22.18)$ & $0.59^{\mathbf{m}}$ \\
\hline & Day 14 & $75.66(18.22)$ & $80.54(18.24)$ & $0.21^{\mathrm{m}}$ \\
\hline & Day 28 & $76.09(19.19)$ & $82.00(19.61)$ & $0.19^{\mathbf{m}}$ \\
\hline \multicolumn{5}{|l|}{ The result of another laboratory } \\
\hline \multirow{3}{*}{ FBS $(74-106 \mathrm{mg} / \mathrm{dL})$} & Day 0 & $104.606(27.06)$ & $116.48(61.15)$ & $0.59^{\mathbf{m}}$ \\
\hline & Day 14 & $105.96(29.34)$ & $114.18(62.12)$ & $0.39^{\mathbf{m}}$ \\
\hline & Day 28 & $104.65(29.41)$ & $113.58(54.26)$ & $0.73^{\mathrm{m}}$ \\
\hline
\end{tabular}


TABLE 5: Continued.

\begin{tabular}{|c|c|c|c|c|}
\hline \multirow{2}{*}{ Data } & \multirow{2}{*}{ Follow-up } & \multicolumn{2}{|c|}{ Treatment* } & \multirow{2}{*}{$p$ value ${ }^{* *}$} \\
\hline & & Sahastara $(n=32)$ & Diclofenac $(n=31)$ & \\
\hline \multirow{3}{*}{ HDL-cholesterol (40-60 mg/dL) } & Day 0 & $55.66(15.18)$ & $58.00(14.31)$ & $0.48^{\mathbf{m}}$ \\
\hline & Day 14 & $55.90(15.51)$ & $57.31(15.55)$ & $0.71^{\mathbf{m}}$ \\
\hline & Day 28 & $57.28(13.58)$ & $53.70(16.09)$ & $0.52^{\mathrm{m}}$ \\
\hline \multirow{3}{*}{ Total cholesterol $(40-60 \mathrm{mg} / \mathrm{dL})$} & Day 0 & $220.63(40.34)$ & $222.03(44.27)$ & $0.85^{\mathbf{m}}$ \\
\hline & Day 14 & $214.35(35.12)$ & $220.65(38.35)$ & $0.37^{\mathbf{m}}$ \\
\hline & Day 28 & $212.00(37.78)$ & $224.51(41.71)$ & $0.18^{\mathbf{m}}$ \\
\hline \multirow{3}{*}{ LDL-cholesterol $(0-150 \mathrm{mg} / \mathrm{dL})$} & Day 0 & $133.39(34.47)$ & $132.63(40.85)$ & $0.82^{\mathrm{m}}$ \\
\hline & Day 14 & $130.27(32.02)$ & $132.00(32.00)$ & $0.74^{\mathrm{m}}$ \\
\hline & Day 28 & $130.25(30.02)$ & $132.54(36.00)$ & $0.76^{\mathrm{m}}$ \\
\hline \multirow{3}{*}{ Triglyceride $(0-150 \mathrm{mg} / \mathrm{dL})$} & Day 0 & $152.66(98.81)$ & $144.64(79.68)$ & $0.98^{\mathbf{m}}$ \\
\hline & Day 14 & $159.90(114.84)$ & $145.13(85.90)$ & $0.84^{\mathbf{m}}$ \\
\hline & Day 28 & $135.09(84.13)$ & $158.68(16.47)$ & $0.53^{\mathrm{m}}$ \\
\hline \multirow{3}{*}{ Live function total protein $(6.4-8.2 \mathrm{mg} / \mathrm{dL})$} & Day 0 & $4.60(3.98)$ & $3.93(0.25)$ & $0.44^{\mathbf{m}}$ \\
\hline & Day 14 & $4.30(3.80)$ & $3.75(0.34)$ & $0.44^{\mathbf{m}}$ \\
\hline & Day 28 & $4.20(3.80)$ & $3.76(0.28)$ & $0.24^{\mathrm{m}}$ \\
\hline \multirow{3}{*}{ Albumin $(3.4-5 \mathrm{mg} / \mathrm{dL})$} & Day 0 & $3.98(0.25)$ & $3.93(0.25)$ & $0.51^{\mathbf{m}}$ \\
\hline & Day 14 & $3.80(0.27)$ & $3.75(0.34)$ & $0.66^{\mathrm{m}}$ \\
\hline & Day 28 & $3.80(0.20)$ & $3.76(45.28)$ & $0.54^{\mathrm{m}}$ \\
\hline \multirow{3}{*}{ Globulin $(1.5-3.5 \mathrm{mg} / \mathrm{dL})$} & Day 0 & $3.70(0.30)$ & $3.85(0.47)$ & $0.51^{\mathbf{m}}$ \\
\hline & Day 14 & $3.65(0.35)$ & $3.76(0.51)$ & $0.66^{\mathrm{m}}$ \\
\hline & Day 28 & $3.56(0.28)$ & $3.73(0.48)$ & $0.54^{\mathbf{m}}$ \\
\hline \multirow{3}{*}{ Total bilirubin $(0.2-1.0 \mathrm{mg} / \mathrm{dL})$} & Day 0 & $0.63(0.37)$ & $0.53(0.28)$ & $0.11^{\mathbf{m}}$ \\
\hline & Day 14 & $0.53(0.34)$ & $0.43(0.16)$ & $0.25^{\mathrm{m}}$ \\
\hline & Day 28 & $0.52(0.23)$ & $0.47(0.21)$ & $0.13^{\mathrm{m}}$ \\
\hline \multirow{3}{*}{ Direct bilirubin $(0.0-0.2 \mathrm{mg} / \mathrm{dL})$} & Day 0 & $0.13(0.07)$ & $0.14(0.12)$ & $0.87^{\mathbf{m}}$ \\
\hline & Day 14 & $0.11(0.05)$ & $0.10(0.03)$ & $0.30^{\mathbf{m}}$ \\
\hline & Day 28 & $0.10(0.04)$ & $0.10(0.04)$ & $0.75^{\mathbf{m}}$ \\
\hline \multirow{3}{*}{ Total alkaline phosphatase (50-136 U/L) } & Day 0 & $74.27(20.18)$ & $78.96(22.18)$ & $0.59^{\mathbf{m}}$ \\
\hline & Day 14 & $75.66(18.22)$ & $80.54(18.24)$ & $0.21^{\mathbf{m}}$ \\
\hline & Day 28 & $76.09(19.19)$ & $82.00(19.61)$ & $0.19^{\mathbf{m}}$ \\
\hline \multirow{3}{*}{ CBC WBC (4.9-11.0 K/cumm) } & Day 0 & $6.37(1.42)$ & $6.25(1.67)$ & $0.68^{\mathbf{m}}$ \\
\hline & Day 14 & $5.83(1.88)$ & $5.77(1.75)$ & $0.92^{\mathbf{m}}$ \\
\hline & Day 28 & $6.09(1.43)$ & $5.98(1.57)$ & $0.81^{\mathbf{m}}$ \\
\hline \multirow{3}{*}{ Neutrophil (45-75\%) } & Day 0 & $52.45(12.26)$ & $52.45(12.26)$ & $0.40^{\mathrm{m}}$ \\
\hline & Day 14 & $51.15(9.11)$ & $51.15(9.11)$ & $0.35^{\mathbf{m}}$ \\
\hline & Day 28 & $52.00(6.99)$ & $52.00(6.99)$ & $0.39^{\mathbf{m}}$ \\
\hline & Day 0 & $37.93(8.27)$ & $37.93(8.27)$ & $0.54^{\mathrm{m}}$ \\
\hline Lymphocyte (20-45\%) & Day 14 & $39.54(8.341)$ & $39.54(8.34)$ & $0.62^{\mathrm{m}}$ \\
\hline & Day 28 & $37.66(6.84)$ & $37.66(6.84)$ & $0.74^{\mathrm{m}}$ \\
\hline & Day 0 & $3.52(01.58)$ & $3.55(01.64)$ & $1.00^{\mathrm{m}}$ \\
\hline Monocyte (2-10\%) & Day 14 & $3.69(01.9)$ & $3.59(01.67)$ & $0.99^{\mathbf{m}}$ \\
\hline & Day 28 & $3.70(01.52)$ & $3.48(02.09)$ & $0.18^{\mathbf{m}}$ \\
\hline & Day 0 & $4.14(3.47)$ & $4.16(4.04)$ & $0.74^{\mathrm{m}}$ \\
\hline Eosinophil (4-6\%) & Day 14 & $4.26(2.41)$ & $4.97(3.87)$ & $0.70^{\mathbf{m}}$ \\
\hline & Day 28 & $4.83(2.48)$ & $6.22(4.43)$ & $0.18^{\mathbf{m}}$ \\
\hline & Day 0 & $0.53(0.25)$ & $0.57(0.75)$ & $0.33^{\mathrm{m}}$ \\
\hline Basophil (0-1\%) & Day 14 & $0.71(01.17)$ & $0.49(0.44)$ & $0.30^{\mathbf{m}}$ \\
\hline & Day 28 & $0.47(0.24)$ & $0.42(0.22)$ & $0.62^{\mathrm{m}}$ \\
\hline & Day 0 & $4.40(0.36)$ & $4.36(0.59)$ & $0.25^{\mathbf{m}}$ \\
\hline $\mathrm{RBC}\left(4.5-6.0 \times 10^{6} /\right.$ cumm $)$ & Day 14 & $4.27(0.65)$ & $4.34(0.63)$ & $0.73^{\mathbf{m}}$ \\
\hline & Day 28 & $4.32(0.40)$ & $4.48(1.10)$ & $0.99^{\mathrm{m}}$ \\
\hline & Day 0 & $12.4(0.98)$ & $14.82(17.60)$ & $0.03^{\mathrm{m}}$ \\
\hline $\mathrm{Hb}(14-18 \mathrm{gm} / \mathrm{dL})$ & Day 14 & $12.14(0.92)$ & $11.66(1.12)$ & $0.14^{\mathbf{m}}$ \\
\hline & Day 28 & $12.01(1.00)$ & $11.71(1.13)$ & $0.33^{\mathrm{m}}$ \\
\hline & Day 0 & $37.20(2.42)$ & $35.58(3.08)$ & $0.36^{\mathbf{m}}$ \\
\hline Hct $(41-51 \%)$ & Day 14 & $36.92(2.41)$ & $35.81(3.52)$ & $0.35^{\mathrm{m}}$ \\
\hline & Day 28 & $36.63(3.08)$ & $35.60(3.50)$ & $0.20^{\mathrm{m}}$ \\
\hline & Day 0 & $275.60(58.63)$ & $284.06(78.23)$ & $0.99^{\mathbf{m}}$ \\
\hline Platelets (150-400 K/cumm) & Day 14 & $286.90(63.08)$ & $283.87(67.26)$ & $0.61^{\mathrm{m}}$ \\
\hline & Day 28 & $288.00(64.26)$ & $290.21(68.90)$ & $0.99^{\mathrm{m}}$ \\
\hline
\end{tabular}

"Data represent mean (SD); ${ }^{* *}$ statistical analysis; ${ }^{\mathrm{m}}$ Mann-Whitney $U$ test. For all within group statistical analysis: repeated measure ANOVA. ${ }^{\dagger}$ Significant difference from day 0 within the group $(P<0.05) ;{ }^{\dagger \dagger}$ significant difference from day 0 within the group $(P<0.01)$. 
TABLE 6: Adverse reaction comparison between Sahastara and diclofenac.

\begin{tabular}{lccc}
\hline Adverse events & $\begin{array}{c}\text { Sahastara, no. } \\
(\%)\end{array}$ & $\begin{array}{c}\text { Diclofenac, no. } \\
(\%)\end{array}$ & $\begin{array}{c}p \\
\text { value }^{\mathrm{C}}\end{array}$ \\
\hline Gastric pain & $0(0)$ & $7(22.58)$ & 0.11 \\
Belching & $10(31.25)$ & $0(0)$ & $0.001^{* *}$ \\
Constipation & $2(6.25)$ & $1(3.22)$ & 0.81 \\
$\begin{array}{l}\text { Dry lips and } \\
\text { throat }\end{array}$ & $4(12.50)$ & $2(6.45)$ & 0.65 \\
Sweating & $1(3.12)$ & $1(3.22)$ & 0.98 \\
Dizziness & $1(3.12)$ & $2(6.45)$ & 0.81 \\
\hline
\end{tabular}

${ }^{\mathrm{C}}$ Chi-square.

be easier for the patients to take. Moreover, taking SHT ethanolic extract which has been standardized [31] enables accurate amount of drug administration with known amount of active ingredient. All these should support the inclusion of the SHT ethanolic extract capsules in the National Essential Drugs List.

However, this research had some limitations with respect to sex of the patients, since we could not do block design to balance the numbers of female and male patients as suggested in the previous study. This was because almost all orthopedic patients in our hospital were female (more than $90 \%)$. Nevertheless, this is the first study on clinical trial phase II of SHT ethanolic extract capsule. Results from this study will form the basis for the continuation of the clinical study into phase III and will encourage further development of this drug.

\section{Conclusion}

This study is the first to evaluate the clinical efficacy and safety of SHT ethanolic extract capsules for the treatment of osteoarthritic knee patients in comparison with the conventional NSAID drug, diclofenac. The SHT ethanolic extract capsule can relieve the inflammation symptoms in OA knee patients almost as effectively as diclofenac, with less minor side effects. Therefore, it can be considered a safe alternative anti-inflammatory drug for the treatment of OA.

\section{Data Availability}

The data supporting the findings of the study are available from the corresponding author upon request.

\section{Conflicts of Interest}

The authors declare that there are no conflicts of interest.

\section{Authors' Contributions}

NK did the whole clinical study. PP and AI are NK's advisors. PP helped in recruiting orthopedic patients and designing the clinical study. PK helped to evaluate the clinical results. AI helped with the preparation and quality control of the drugs for the research and helped write the manuscript. BO proofread, made suggestions on revision, and edited the manuscript. AI provided the research grant and helped in all aspects of the experiments including evaluation of the results on drug preparations, writing of the manuscript, and acting as the corresponding author.

\section{Acknowledgments}

This study was supported by National Research Council of Thailand, Center of Excellence in Applied Thai Traditional Medicine, and Bualuang ASEAN Chair Professorship, Faculty of Medicine, Thammasat University, Thailand.

\section{References}

[1] S. Ninkanuwang, Text book of Osteoarthritis, vol. 2, S.P.N Printing, Bangkok, Thailand, 2005.

[2] M. Persson, J. Stocks, G. Varadi et al., "Predicting response to topical non-steroidal anti-inflammatory drugs in osteoarthritis: an individual patient data meta-analysis of randomized controlled trials," Rheumatology, vol. 59, no. 9, pp. 2207-2216, 2005.

[3] Y. Zheng, X. Duan, S. Qi et al., "Acupuncture therapy plus hyaluronic acid injection for knee osteoarthritis: a metaanalysis of randomized controlled trials," Evidence-Based Complementary and Alternative Medicine, vol. 2020, Article ID 4034105, 10 pages, 2020.

[4] A. Askari, S. A. Ravansalar, M. Naghizadeh et al., "The efficacy of topical sesame oil in patients with knee osteoarthritis: a randomized double-blinded active-controlled non-inferiority clinical trial," Complementary Therapies in Medicine, vol. 47, Article ID 102183, 2019.

[5] N. Koonrungsesomboon, S. Teekachunhatean, S. Chansakaow, and N. Hanprasertpong, "Clinical efficacy and safety of yellow oil formulations 3 and 4 versus indomethacin solution in patients with symptomatic osteoarthritis of the knee: a randomized controlled trial," Evidence-Based Complementary and Alternative Medicine, vol. 2020, Article ID 5782178, 10 pages, 2020.

[6] N. Kakatum, "Anti-inflammatory activity of Thai traditional remedy extract for muscle pain treatment called Sahastara and its plant ingredients," M.S. Thesis, Applied Thai Traditional Program, Thammasat University, Bangkok, Thailand, 2011.

[7] B. Sripanidkulchai, "Mutagenicity and antimutagenicity tests of extracts from Thai traditional medicines," KKU Research Journal, vol. 12, no. 4, pp. 492-498, 2007.

[8] P. Pinsornsak, P. Kanokkangsadal, and A. Itharat, "The clinical efficacy and safety of the Sahastara remedy versus diclofenac in the treatment of osteoarthritis of the knee: a double-blind, randomized, and controlled trial," EvidenceBased Complementary and Alternative Medicine, vol. 2015, Article ID 103046, 8 pages, 2015.

[9] K. Srisook, S.-S. Han, H.-S. Choi et al., "CO from enhanced $\mathrm{HO}$ activity or from CORM-2 inhibits both $\mathrm{O} 2-$ and $\mathrm{NO}$ production and downregulates HO-1 expression in LPSstimulated macrophages," Biochemical Pharmacology, vol. 71, no. 3, pp. 307-318, 2006.

[10] N. Singh, S. Kumar, P. Singh et al., "Piper longum Linn. Extract inhibits TNF- $\alpha$-induced expression of cell adhesion molecules by inhibiting NF- $\kappa \mathrm{B}$ activation and microsomal lipid peroxidation," Phytomedicine, vol. 15, no. 4, pp. 284-291, 2008.

[11] F. Tasleem, I. Azhar, S. N. Ali, S. Perveen, and Z. A. Mahmood, "Analgesic and anti-inflammatory activities 
of Piper nigrum L." Asian Pacific Journal of Tropical Medicine, vol. 7, pp. S461-S468, 2014.

[12] Y. Liu, VR. Yadev, BB. Aggarwal, and MG. Nair, "Inhibitory effects of black pepper (Piper nigrum) extracts and compounds on human tumor cell proliferation, cyclooxygenase enzymes, lipid peroxidation and nuclear transcription factorkappa-B," Natural Product Communications, vol. 5, no. 8, pp. 1253-1257, 2014.

[13] S. Makchuchit, A. Itharat, and S. Tewtrakul, "Antioxidant and nitric oxide inhibition activities of Thai medicinal plants," Journal of the Medical Association of Thailand, vol. 93, no. 7, pp. S227-S235, 2010.

[14] GS. Bae, MS. Kim, WS. Jung et al., "Inhibition of lipopolysaccharide-induced inflammatory responses by piperine," European Journal of Pharmacology, vol. 642, no. 1-3, pp. 154-162, 2010.

[15] J. S. Bang, D. H. Oh, H. M. Choi et al., “Anti-inflammatory and antiarthritic effects of piperine in human interleukin $1 \beta$ stimulated fibroblast-like synoviocytes and in rat arthritis models," Arthritis Research \& Therapy, vol. 11, no. 2, p. R49, 2009.

[16] P. Nootim, A Comparative of Efficacy between Sahasthara and Diclofenac Tablet for Muscle Pain Relief. Thesis Faculty of Pharmacy Program in Consumer Protection in Public Health, Silpakorn University, Bangkok, Thailand, 2010.

[17] P. Kanokkangsadal, P. Wanichsetakul, and A. Itharat, "The clinical safety of Sahastara remedy ethanolic extract capsules in healthy," Journal of the Medical Association of Thailand, vol. 101, pp. 1429-1436, 2018.

[18] A. Itharat, P. Kanokkangsadal, P. Khemawoot, P. Wanichsetakul, and N. Davies, "Pharmacokinetics of piperine after oral administration of Sahastara remedy capsules in healthy volunteers," Research in Pharmaceutical Sciences, vol. 15, no. 5, pp. 410-417, 2020.

[19] B. Tangtrakulwanich, S. Wiwatwongwana, V. Chongsuvivatwong, and A. F. Geater, "Comparison of validity, and responsiveness between general and diseasespecific quality of life instruments (Thai version) in knee osteoarthritis," Journal of the Medical Association of Thailand=Chotmaihet Thangphaet, vol. 89, no. 9, pp. 1454-1459, 2006.

[20] WHO, Toxicity Grading Scale for Determining the Severity of Adverse Events, WHO, Geneva, Switzerland, 2003.

[21] S. P. J. Verkleij, P. A. J. Luijsterburg, A. M. Bohnen, B. W. Koes, and S. M. A. Bierma-Zeinstra, "NSAIDs vs acetaminophen in knee and hip osteoarthritis: a systematic review regarding heterogeneity influencing the outcomes," Osteoarthritis and Cartilage, vol. 19, no. 8, pp. 921-929, 2011.

[22] U.S. Department of Health and Human Services, Guidance for Industry Toxicity Grading Scale for Healthy Adult and Adolescent Volunteers Enrolled in Preventive Vaccine Clinical Trials, Food and Drug Administration ,Center for Biologics Evaluation and Research, Washington, DC, USA, 2007.

[23] L. Hlavackova, A. Urbanova, O. Ulicna, P. Janega, A. Cerna, and P. Babal, "Piperine, active substance of black pepper, alleviates hypertension induced by NO synthase inhibition," Bratislavske Lekarske Listy, vol. 111, no. 8, pp. 426-431, 2010.

[24] S. Corbett, J. Daniel, R. Drayton, M. Field, R. Steinhardt, and N. Garrett, "Evaluation of the anti-inflammatory effects of ellagic acid," Journal of Perianesthesia Nursing, vol. 25, no. 4, pp. 214-220, 2010.

[25] S.-H. Kim, C.-D. Jun, K. Suk et al., "Gallic acid inhibits histamine release and pro-inflammatory cytokine production in mast cells," Toxicological Sciences, vol. 91, no. 1, pp. 123-131, 2006.

[26] W. Chang and J. Teng, " $\beta$-asarone prevents A $\beta 25$-35-induced inflammatory responses and autophagy in SH-SY5Y cells: down expression Beclin-1, LC3B and up expression Bcl-2," International Journal of Clinical and Experimental Medicine, vol. 8, no. 11, pp. 20658-20663, 2015.

[27] R. Checker, D. Sharma, S. K. Sandur et al., "Plumbagin inhibits proliferative and inflammatory responses of $\mathrm{T}$ cells independent of ROS generation but by modulating intracellular thiols," Journal of Cellular Biochemistry, vol. 110, no. 5, pp. 1082-1093, 2010.

[28] M. S. Hashemi, M. H. Hashempur, M. H. Lotfi et al., "The efficacy of asafoetida (Ferula assa-foetida oleo-gum resin) versus chlorhexidine gluconate mouthwash on dental plaque and gingivitis: a randomized double-blind controlled trial," European Journal of Integrative Medicine, vol. 29, Article ID 100929, 2019.

[29] S. Morten, S. H. Toft, and P. Lars, "Diclofenac use and cardiovascular risks: series of nationwide cohort studies," British Medical Journal, vol. 362, Article ID k3426, 2018.

[30] S. Booranasubkajorn, S. Huabprasert, J. Wattanarangsan et al., "Vasculoprotective and vasodilatation effects of herbal formula (Sahatsatara) and piperine in spontaneously hypertensive rats," Phytomedicine, vol. 24, pp. 148-156, 2017.

[31] P. Kanokkangsadal, P. Wanichsetakul, and A. Itharat, "The stability of Sahastara remedy ethanolic extract used for application in clinical study," Thammasat Medical Journal, vol. 18, no. 4, pp. 1-9, 2019. 